\title{
An Overview Of Nanonet Based Dye-Sensitized Solar Cell (DSSC) In Solar Cloth
}

\author{
Mohd Azlishah Othman, Badrul Hisham Ahmad, and Noor Faridah Amat
}

\begin{abstract}
This technical paper contains the information of the Dye-Sensitized Solar Cells (DSSC) working principal where diffusion mechanism acts as electron transport to absorb the sunlight energy to generate the electrical energy. DSSC is photo electrochemical cell that implements the application of photosynthesis process. The performance of electron transport in DSSC has been reviewed in order to enhance the performance and efficiency of electron transport. The improvement of the electron transport also discussed in this paper.
\end{abstract}

Index Terms-DSSC, electron tranport, difusion mechanism

\section{INTRODUCTION}

Nowadays green technology field become a key element in research area recently. Researchers recently explore this field to research a new technology in order to produce a clean energy that will use in daily life. Depletion of fossil energy led the renewable energy become important and demand. This area challenging researchers to ensure the new technology becomes clean, low cost and high efficiency. Harnessing energy from sun rays becomes a best method to generate electrical energy to contribute energy in daily life. Prof Michael Gratzel was invented dye-sensitized solar cell and

Manuscript received May. 14, 2013; accepted Sep. 9, 2013 Centre for Telecommunication Research and Innovation (CeTRI), Faculty of Electronics and Computer Engineering,

Universiti Teknikal Malaysia Melaka, Hang Tuah Jaya, 76100 Durian Tunggal, Melaka, Malaysia

E-mail : azlishah@utem.edu.my demonstrated for first time in 1991 [1, 2], that promising low manufacturing cost technology to harvest energy from the sunlight [3]. Today, DSSC become popular area to explore for some researchers in order to improve the efficiency of the DSSC itself or applied it in photovoltaic devices.

Solar cloth is photovoltaic device, which is made from non-woven fiber cloth in which a dye-anchored wide band gap semiconductor is applied. The electron conductor in semiconductor will be forming a percolating network in a polymeric hole-conducting medium. Thus, to develop solar cloth, one-dimensional nanowires would be considered as a network or also known as nanonet. The network of one-dimensional nanowires would have superior percolation behavior compared to nanoparticles analogues. So those, by implying the dye-sensitized solar cell technique and by transforming the nanoparticles to nanowires in the solar cloth, this device operate efficiently. Then, the solar cloth will able to absorb the sunlight to generate the electrical energy. Moreover, the transformation to nanowires will be enhancing the electron transport in the solar cloth, the nanowires will be implementing as a medium for electron to transport in the solar cloth efficiently. The device would be operational when there is a percolating network of nanowires also known as nanonets, in a polymeric medium containing dye-anchored semiconductor and the hole-conducting polymer or electrolyte and it has a potential to be developed as a deployable technology in nonconventional device areas such as window curtains, protective clothing, tends and in addition to other functional membranes such as the one required for photoelectrochemical water splitting.

In this paper, the working principle of DSSC act as a 
network of solar cloth has been reviewed in section II that include the diffusion mechanism as the electron transport and also the nanowires as a new medium of electron transport to enhance the transporting process in the solar cloth. Section III describe about nanowires and the a few comparison of the synthesis of nanowires while in section IV and V, the performance of nanowires based DSSC have been reviewed and conclusion of this paper.

\section{DYE-SENSITIZED SOLAR CELL (DSSC)}

Basically, for any solar cells working principle, there are 3 basic operation consists of absorption, separation and collection [4]. Each of solar cells optimizes the different working principle to attain better efficiency. For DSSC, it applied absorption process to absorb the photon from the sun rays and it categorized as a liquid/solid junction type solar cell that is often referred to as photo electrochemical cell in which dye-sensitized n-type semiconducting oxide serve as working electrode also known as photoanaode $[5,6]$.

The dye-sensitized solar cell (DSSC) is a third generation photovoltaic device that promises low manufacturing cost to conversion energy. DSSC is based on a nanostructured, mesoporous metal oxide film, sensitized to the visible light by an adsorbed molecular dye [7]. The DSSC are fabricated by sandwiching a dyeanchored mesoporous metal oxide, known as photoelectrode, between two conducting glass plates (such as fluorine-doped indium tin oxide (FTO)) in the presence of an electrolyte [8]. In order to improve the efficiency of solar energy conversion, the light harvesting efficiency, electron injection efficiency and undesirable electron lifetime should be measured [2]. Basically, there are 4 key components that include a light source, semiconductor, sensitizer and the electrolyte in DSSC [4] which is play important role in the DSSC. Each of the components has their own function. Their functions as shown in table below while in Fig. 1 illustrate all the components in the solar cell that also include the external circuit to ensure the electron will flow to the back contact of solar cell. Then it process will be going continuously.

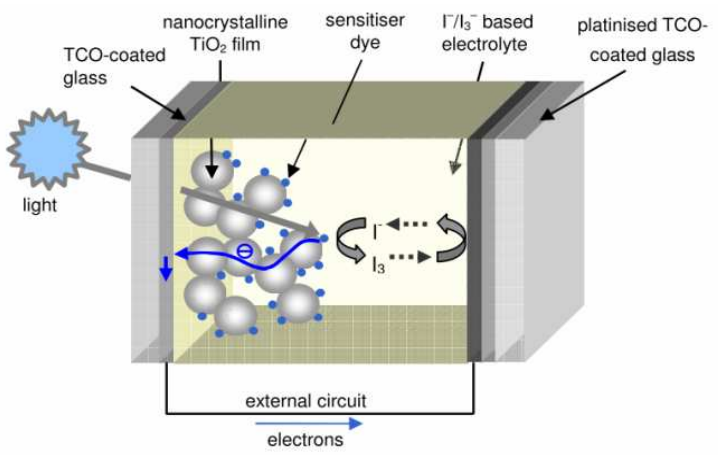

Fig. 1. Schematic of a liquid electrolyte DSSC with external circuit [9].

\section{Working Principle}

The DSSC principle is applied from the photosynthesis process and diffusion is a major mechanism for electron to travel through the oxide layer [10]. The working principle of DSSC involved several steps as shown in Fig. 3. The steps involved:

(a) Under illumination, the photon from the sunrays will be striking the DSSC device. According to Eq. (1), the sensitizer, $\mathrm{S}$ absorbs a photon of wavelength, $\mathrm{hv}$ corresponding to the energy difference between its highest occupied molecular orbital (HOMO) and lowest unoccupied molecular orbital (LUMO) which leads to excited sensitizer state, $\mathrm{S}^{*}$ known as photo excitation.

(b) Photo excitation, $\mathrm{S}^{*}$ of this sensitizer is then injected the electron,e refer to Eq. (2), which travel through the nanostructured film by diffusion into the conduction band of the semiconductor (mesoporous), usually using $\mathrm{TiO}_{2}$ (high band gap: $3.2 \mathrm{eV}$ ) to reach TCO on glass substrate as a current collector. Meanwhile according to [3], the hole generated by photon excitation remains on the molecule during this process, since the HOMO of dye is separated from all other energy levels of the device. There is no energy channel for the hole to diffuse into $\mathrm{TiO}_{2}$ photoanode. As a result, the hole is eventually filled up by electrons from electrolyte ions, which conduct current between the cathode and the dye molecule.

(c) The injected electron,e flows through the semiconductor network to arrive at the back contact by through the external load.

(d) By referring Eq. (3), the injected electron,e at back contact react in reduction of oxidized dye by iodide 
produces triiodide, $\mathrm{I}_{3}^{-}$to reduce the redox mediator. At the same time, the triiodide, $\mathrm{I}_{3}^{-}$diffuses to counter electrode and accepts electrons from external load, regenerating the iodides [3].

(e) Then, iodide wills donates electron to the oxidized sensitizer, S+ that obtained at anode from Eq. (2) and regenerates the sensitizer which in turn regenerates the sensitizer as shown in Eq. (4).

(f) However, Eqs. (5) and (6) are undesirable reactions either with oxidized sensitizer or with the oxidized redox couple at the $\mathrm{TiO}_{2}$ surface. Consequently, performance of the cell will be affect.

This process go in cycle and consequently current flows through the external circuit as long as light is incident on the cell [1]. The equations below show the reaction of the sensitizer and electron in the DSSC [2-5] that have been explained.

$$
\begin{aligned}
& S_{(a b s o r b e d)}+h v \longrightarrow S_{(\text {absorbed) }}^{*} \\
& S_{(\text {absorbed) }}^{*} \longrightarrow S_{(\text {absorbed) }}^{+}+e_{(\text {injected) }}^{-} \\
& I_{3}^{-}+2 \cdot e^{-} \text {(cathode) } \longrightarrow 3 I_{\text {(cathode) }} \\
& S_{(\text {absorbed) }}^{+}+\frac{3}{2} I^{-} \longrightarrow S_{(\text {absorbed })}+\frac{1}{2} I_{3}^{-} \\
& S^{+}{ }_{\text {(absorbed) }}+e^{-}\left(\mathrm{TiO}_{2}\right) \longrightarrow S_{\text {(absorbed) }} \\
& I_{3}^{-}+2 e^{-}\left(\mathrm{TiO}_{2}\right) \longrightarrow 3 I^{-} \text {(anode) }
\end{aligned}
$$

By referring the above figure, it shows the illustration of electron movement in the first step until to last step. This process will go on continuously as long as the sun rays incident on the cell. According to Fig. 2, the maximum voltage in DSSC is determined by the energy separation between Fermi level and the electrolyte chemical potential (Eredox). The photocurrent level is dependent on the separation level of HOMO-LUMO as example, if the energy separation of LUMO is increase, it will improve the electron injection into the conduction band of $\mathrm{TiO}_{2}$ effectively [11]. Besides, if the HOMO level accept the donated electrons from redox mediator effectively, it show that the energy different between the HOMO and redox mediator is positive.

We can conclude that photo voltage is generally determined by the energy difference between the Fermi level of $\mathrm{TiO}_{2}$ and redox potential of electrolyte. The anode-cathode potential difference, namely, the opencircuit voltage Voc, is mainly determined by the difference between conduction band bottom and

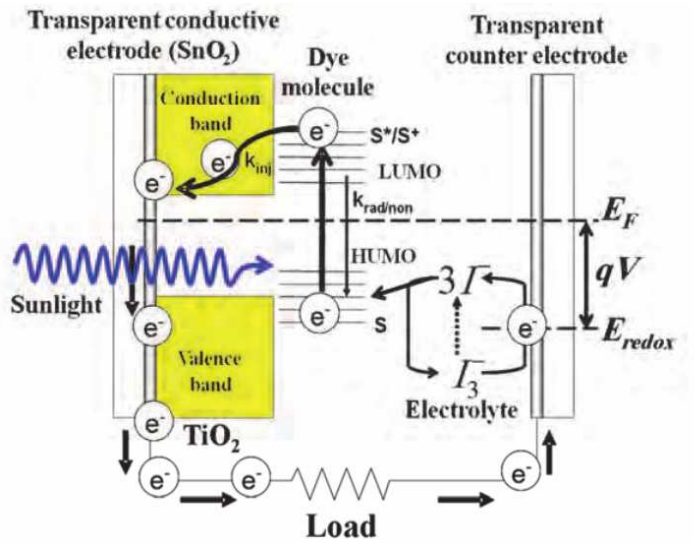

Fig. 2. Schematic illustration of electron movement of dye sensitized solar cell [11].

electrolyte anion energy level [3]. At short-circuit condition, the Fermi energy level decreases in the direction of the back contact (charge collector) due to difference in electron concentration with $\mathrm{TiO}_{2}$ film distance. On the other hand, at open- circuit condition the Fermi energy level is constant across the entire film [12].

\section{Structure of DSSC}

The dye-sensitized solar cell is implying from photosynthesis where it converts the energy from sunrays that absorbed by pigments into other forms of energy same as the DSSC process. The energy from sunrays will

be absorbing by dyes or sensitizer and convert it into other forms. In the photosynthesis process, the sunrays are converted into chemical energy where glucose will be produced. Otherwise, in DSSC process, the energy is absorbed by dye or sensitizer to generate the electrical energy. In this section, the structure of DSSC is discussed.

\section{a) $\mathrm{TiO}_{2}$ (semiconductor electrode)}

Many researcher use $\mathrm{TiO}_{2}$ as semiconductor material compare to other such $\mathrm{ZnO}, \mathrm{SnO}_{2}$, and $\mathrm{Nb}_{2} \mathrm{O}_{5}[7,13,14]$. This is because $\mathrm{TiO}_{2}$ band gap is higher than other like Fig. 3. Fig. 3 shows the energy levels of the conduction band and the valence band of $\mathrm{TiO}_{2}, \mathrm{ZnO}$ and $\mathrm{SnO} 2$ where energy level of $\mathrm{SnO}_{2}$ less than $\mathrm{TiO}_{2}$ and $\mathrm{ZnO}$. Even though $\mathrm{TiO}_{2}$ and $\mathrm{ZnO}$ show same value of energy level, the ability of both material is differ. The efficiency of $\mathrm{ZnO}$ to harvest energy is less compare to $\mathrm{TiO}_{2}[8,13]$. 


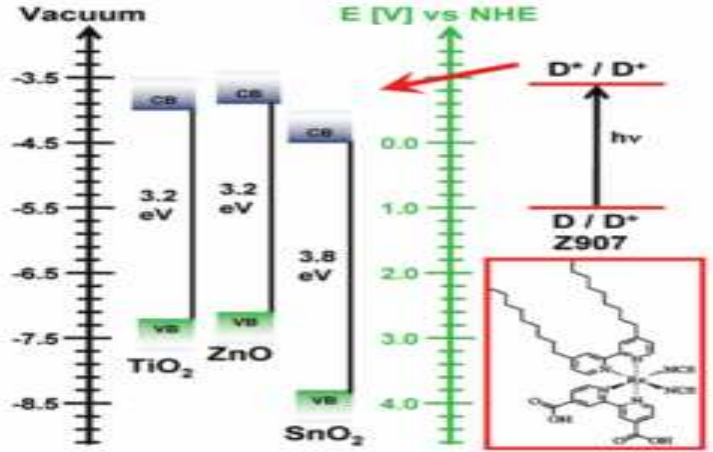

Fig. 3. Schematic diagram illustrating the energy levels of the conduction band (CB) and valence band (VB) of $\mathrm{TiO}_{2}, \mathrm{ZnO}$, and $\mathrm{SnO}_{2}[14]$.

Furthermore, $\mathrm{TiO}_{2}$ material is cheap, nontoxic, biocompatible, chemically stable, have higher refractive index $[8,15,16]$. According to [2], $\mathrm{TiO}_{2}$ paste is applied to the conductive glass and sintered at around $450-500^{\circ} \mathrm{C}$, producing a $\mathrm{TiO}_{2}$ film about $10 \mu \mathrm{m}$ in thickness and then the conductive glass is put into a dye bath, the dye will be adsorbed on the $\mathrm{TiO}_{2}$ surface in a monolayer. Thus, if the nanoporous $\mathrm{TiO}_{2}$ film has a high roughness factor, the amount of dye adsorbed is drastically increased and tiny particles (with diameters of 10 to $30 \mathrm{~nm}$ ) of $\mathrm{TiO}_{2}$ are connected to each other. Besides, the porosity of the $\mathrm{TiO}_{2}$ film is also important because the electrolyte, which contains the redox ions, must be able to penetrate the film effectively to suppress the rate-determining step via diffusion of redox ions into the film.

\section{b) Dye}

The dye is attached to the porous $\mathrm{TiO}_{2}$ layer is essential $[2,17]$ in order to achieve a high light to energy conversion efficiency [17]. Dye molecules of proper molecular structure are used to sensitized wide bandgap nanostructured photo electrode. Upon absorption of photon, a dye molecule adsorbed to the surface of semiconductor, $\mathrm{TiO}_{2}$ gets oxidized and the excited electron is injected into the conduction band of semiconductor, $\mathrm{TiO}_{2}$ [18]. There are a lot of sensitizers type but, $\mathrm{Ru}$ complex is the most efficient that produced more than $11 \%$ of conversion from the light to electrical power [19] and the chemical structure of the Ru complex have verified it to be a better sensitizer [4, 13]. To efficiently operate DSSC, the dye sensitizer that is adsorbed on the surface of the nanoporous $\mathrm{TiO}_{2}$ transfers an electron to $\mathrm{TiO}_{2}$ and is then regenerated by an

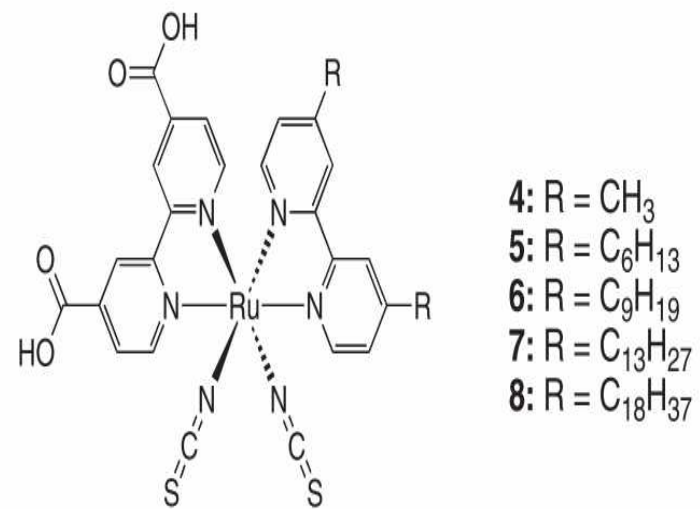

Fig. 4. Schematic of dye sensitizer, Ru complex [15].

electrolyte or p-type conductor. Consequently, intimate contact between the latter and dye sensitizer is essential for perfect charge separation [20]. Fig. 4 illustrate Rucomplex that act as dye sensitizer in the DSSC. The Rucomplex will dye in the surface of semiconductor material $\left(\mathrm{TiO}_{2}\right)$ to increase the capability of the $\mathrm{TiO}_{2}$ to absorb the photon.

\section{c) Electrolyte}

In DSSC, the electrolyte contains a redox couple usually use iodide, $\mathrm{I}^{-}$or triiodide, $\mathrm{I}_{3}^{-}$. When the injected electron at back counter electrode, the electron reacts with iodide, I- to produce triiodide, $\mathrm{I}_{3}^{-}$to reduce mediator. Then the triiodide, $\mathrm{I}_{3}^{-}$diffuse at the counter electrode to regenerate iodide that it will be reacts with sensitizer absorbed, $\mathrm{S}^{+}$to helps the sensitizer or dye to restore in DSSC. In this stage, the undesirable reactions will be occurred such in Eqs. (5) and (6) also known as charge recombination that affects the open circuit voltage by decreasing the concentration of electrons in the conduction band of semiconductor [6]. This reaction can cause the DSSC performance decreased. The undesirable reactions will discuss in the next part.

\section{d) Counter electrode}

Counter electrode can be prepared in parallel to the working electrode deposition [21]. As we explained before, the injected electron conduct the electricity will travel through the conducting electrode and load to reach the counter electrode. At the counter electrode, the injected electron reacts with iodide to produce triiodide. Then the triiodide diffuse at the counter electrode to regenerates the iodide [2]. 


\section{Electron Transport Performance}

The performance of electron transport play important role in the DSSC device. Recently, some researchers have been explored the transporting of electron. In the DSSC, diffusion is the major mechanism for electron to travel through $[6,10]$. Today, some researchers use $\mathrm{TiO} 2$ as metal oxide semiconductor layer because of the material is cheap, chemically stable and non-toxic material, biocompatible, and have higher refractive index $[8,15,16,22]$. Furthermore, the wide band gap of $\mathrm{TiO}_{2}$ is higher than other materials such $\mathrm{ZnO}, \mathrm{SnO}_{2}$ etc. like shown in Fig. 4. In DSSC, $\mathrm{TiO}_{2}$ act as electron acceptor and electron transport layer [12], the sensitizer absorbs photons, electrons on the ground state of the sensitizer are excited to the excited state, which are injected into the conduction band of metal oxide layer within picoseconds to femtosecond, while electrolyte such I-/I-3 acts as hole transport layer where there is no electrical energy. Then, the hole will eventually fill up by electron from electrolyte ions, which conduct current between the cathode and the dye molecule. In the electrolyte, iodide or triiodide will generates and regenerates each other to ensure the DSSC works continuously. In order to restore the sensitizer, the iodide is needed by diffusing the triiodide at the back counter electrode, thus the Eq. (3) is applied.

Actually, the iodide and triiodide is best solvent act as electrolyte in DSSC because of the slow recombination kinetics between electrons in the titania with the oxidized dye and the triiodide in the electrolyte, which leads to long-lived electron lifetimes (between $1 \mathrm{~ms}$ and $1 \mathrm{~s}$ ) [23]. Fig. 6 shows the process reaction of iodide and triiodide that also include the possible recombination process. By referring to [23], state that the small size of the iodide and triiodide, redox components allows for relatively fast diffusion within the mesopores, and the two-electron system allows for a greater current to be passed for a given electrolyte concentration. Unfortunately, the iodide and triiodide system is corrosive and dissolves many of the commonly used sealants and metal interconnects (such as silver, copper, aluminium and gold).

However, there are undesirable reactions, which are the injected electrons may recombine either with oxidized sensitizer (Eq. (5)) or with the oxidized redox couple at the $\mathrm{TiO}_{2}$ surface (Eq. (6)), resulting in losses in

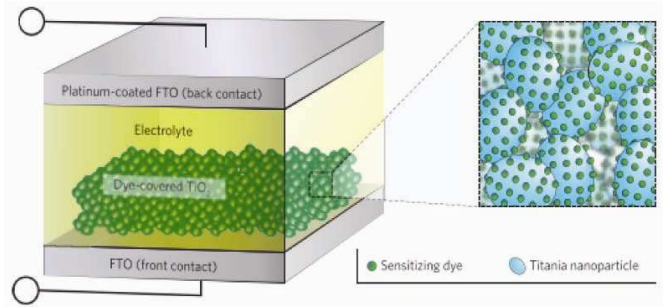

(a)

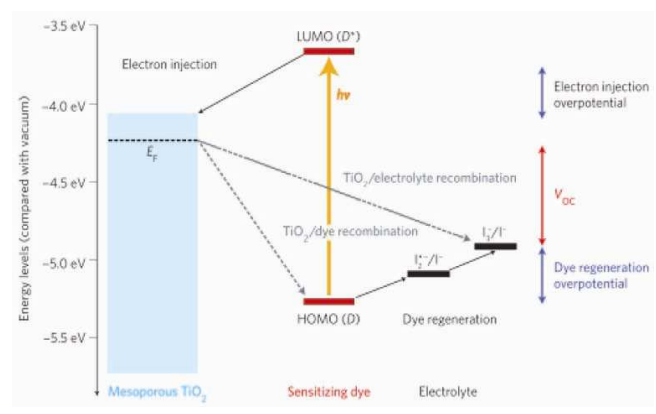

(b)

Fig. 5. Dye-sensitized solar cell device schematic and operation (a) Liquid-based DSCs are comprised of a transparent conducting oxide (such as fluorine-doped tin oxide, FTO) on glass, a nanoparticle photoanode (such as titania) covered in a monolayer of sensitizing dye, a hole-conducting electrolyte and a platinum-coated, FTO-coated glass back-contact, (b) Energy level and device operation of DSCs; the sensitizing dye absorbs a photon (energy $h v$ ), the electron is injected into the conduction band of the metal oxide (titania) and travels to the front electrode (not shown). The oxidized dye is reduced by the electrolyte, which is regenerated at the counter-electrode (not shown) to complete the circuit. $V_{\mathrm{OC}}$ is determined by the Fermi level $(E \mathrm{~F})$ of titania and the redox potential $\left(\mathrm{I}_{3}^{-} / \mathrm{I}^{-}\right)$of the electrolyte [23].

the cell efficiency $[1,2,24]$. Even though the electron diffusion through the metal oxide layer faster than the electron recombination with oxidized dyes on the $\mathrm{TiO}_{2}$ surface or I-3 in the electrolyte for achieving an efficient DSSC, trapping or detrapping events, (Eqs. (5) and (6)) will be occur consequence slow electron transport rate in this layer [10]. This event makes the performance of DSSC decreased and inefficiently. Fig. 6 shows the stage of recombination reaction of electron occur in the DSSC and Fig. 7 show how the trap event will be occur by capturing the injected electron [6]. In order to improve the performance of electron transport in DSSC, we considered nanowires as a new medium for transporting the electron in DSSC. 


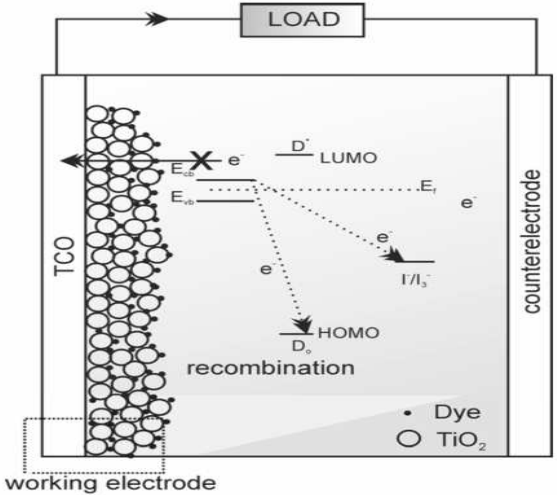

Fig. 6. Possible recombination process [17].

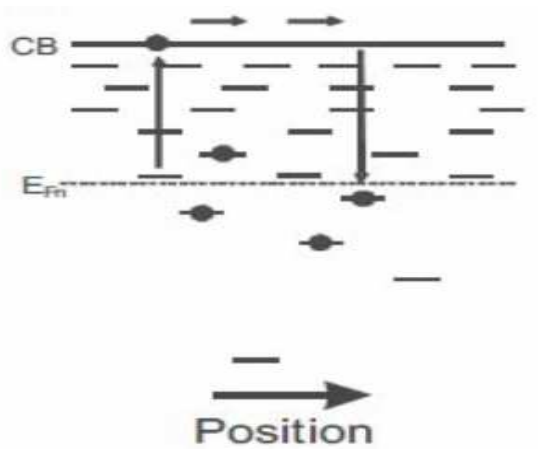

Fig. 7. Schematic illustration of the trap distribution and the multiple trapping-detrapping processes occurring in mesoporous titania [2].

\section{NANOWIRES}

Recently, nanostructures materials have been explored broadly as one components of the photovoltaic device [25]. Nanowires are used to describe a large aspect ratio $1-100 \mathrm{~nm}$ in diameter and also known as nanorods or nanotubes or quantum wires or one dimensional wires. There are different types of nanowires; metallic (Ni, Pt, $\mathrm{Au})$, semiconducting $\left(\mathrm{Si}, \mathrm{GaN}, \mathrm{TiO}_{2}\right)$ and insulating $\left(\mathrm{SiO}_{2}\right)$. Nanowires have two quantum confined directions and one unconfined direction for electrical conduction that allows NWs to direct the conduction of quantum particles such as electrons, phonons, and photons [26, 27]. Nanowires have been utilized as medium to improve the charge collection efficiency in the solar cell. The nanowires are one-dimensional nanostructures that consists of several families such quantum dots, semiconductor nanowires, and carbon materials such as graphene and nanotubes which is play an important role in future for nanoscale devices and circuits, such electronic, optoelectronic and miniaturized biomedical devices [28-30].

In the solar cloth, the nanowires are utilizing as a medium of electron transport from valence band to conduction band and to improve the charge collection efficiency of solar cloth. However, there are a few techniques to synthesis the nanowires.

\section{Synthesis of Nanowires (NWs)}

In order to develop NWs as medium of electron transport in solar cell, there are a few type of synthesis NWs, such as vapor-liquid-solid (VLS), vapor-solidsolid (VSS), chemical vapor deposition (CVD-VLS) [31], hot filament chemical vapor deposition (HFCVD) [32], metal-organic chemical vapor deposition (MOCVD) [33], hydrothermal [34], sol gel process [35], heating sol gel template [36], template-assisted electrodeposition [37], thermal evaporation [38] and more. Each of the types has their own advantage or disadvantage.

Vapor-liquid-solid (VLS) is the most well-established method to produce NWs [39], typically the process involve of four in sequence step and an appropriate metal catalyst is essential for NW growth [31] where, firstly transport of the vapor phase precursor at the catalyst surface and adsorption and desorption between the precursor and the catalyst occurred, after that material diffusion across the liquid alloy catalyst, and the precipitation of solid crystals forming the NW morphology. Compare to VSS process, the catalyst (alloy) is in a solid phase that exhibits a different sticking probability of precursor molecules, diffusivity of adatoms, and phase transformation behavior of the solid alloy. Thus the precipitation rate of NWs in VSS process at the catalyst-NW interface can be radically different from that of a VLS process [31]. Although vapor deposition method is the best method to produce NWs but the following step involve in this method is difficult. Compare to the wet chemistry or hydrothermal method which is simple and easy to handle in the laboratory. The procedure of sol gel method and heating sol gel template is actually same. The difference of both methods is in the heating sol gel template, use AAM template to dip in the $\mathrm{TiO}_{2}$ sol [36] while in the sol gel process, acetic acid $(\mathrm{AcOH})$ will be used as a $\mathrm{TiO}_{2}$ sol modifier to influence the $\mathrm{TiO}_{2}$ morphology [35].

Actually, there are a large number of experimental 
methods to synthesize nanowires such combining sol-gel processing with electrophoretic deposition, the spin-on process, anodic oxidative hydrolysis, sonochemical synthesis and more [40]. Hydrothermal method is a simple method which is where reaction among $\mathrm{TiO}_{2}$ powders with alkaline solution [41] and the best method to synthesize nanowire recently. The advantage of this technique is that nanorods can be obtained in relatively large amounts [40].

In the making of solar cloth, the $\mathrm{TiO}_{2}$ powders are used to synthesis NWs. The simple process is $2 \mathrm{~g}$ of titanium dioxide, $\mathrm{TiO}_{2}$ (Degussa, P25) will be added into $10 \mathrm{M}$ of $50 \mathrm{~mL} \mathrm{NaOH}$ aqueous solution. The solution was then poured into a Teflon-lined stainless-steal autoclave and heated at temperature $120 \mathrm{C}$ for 24 hour. The reaction was allowed to cool naturally at room temperature. The products of white precipitates were collected by centrifuge, and then washed thoroughly with $0.1 \mathrm{M} \mathrm{HCl}$ and deionized water several times until the $\mathrm{pH}$ level reached 7. Then, the samples were dried overnight at 60C in an oven. Then, the final product was collected, which was a very fine white powder. Furthermore, by referring Table 2, this paper concludes all the several techniques or processes have been used in hydrothermal and chemically method in different heat temperature and time and in washing treatment.

\section{NANOWIRES BASED DYE-SENSITIZED SOLAR CELL}

Semiconductor nanowires (NWs) such as $\mathrm{TiO}_{2}, \mathrm{ZnO}$, $\mathrm{SnO}_{2}, \mathrm{Nb}_{2} \mathrm{O}_{5}$, and $\mathrm{SrTiO}_{3}$ represent as a new class of materials that have a unique system with dimensions of very few to several hundreds of nanometers in diameter and several micrometers in length and play an important role in future electronic and optoelectronic devices [27, $28,34]$. In the DSSCs, photoanodes is the most important part [43] which is as function to adsorb dye molecules and transport the injected electrons. The performance of the photovoltaic device highly dependent on its size [43], structure and morphology of semiconductor [43, 44]. The morphology of semiconductor provides high surface area to maximize dye absorption and efficient electron transport that delivers the electron to the collection electrode without recombination and the same improved the performance of DSSC [45, 46],
Table 2. Nanotubes of Different Structures Prepared from Different $\mathrm{TiO}_{2}$ Precursors, $\mathrm{NaOH}$ Treatment Conditions, ${ }^{\mathrm{a}}$ and Post-Treatment Washing Processes (in sequence) [34]

\begin{tabular}{|c|c|c|}
\hline Precursor & $\mathrm{NaOH}$ treatment ${ }^{\mathrm{a}}$ & Post-treatment \\
\hline \multicolumn{3}{|c|}{ Nanotube structure: Anatase $\mathrm{TiO}_{2}$} \\
\hline $\begin{array}{c}\text { Anatase } \\
\text { Rutile } \\
\text { Anatase } \\
\text { Anatase } \\
\text { Anatase } \\
\text { Anatase } \\
\text { Anatase/Rutile } \\
\text { Anatase }\end{array}$ & $\begin{array}{l}\text { Hydro/110/20 } \\
\text { Chem/110/20 } \\
\text { Chem/150/12 } \\
\text { Hydro/110/20 } \\
\text { Chem/110/20 } \\
\text { Hydro/150/12 } \\
\text { Hydro/130/24 } \\
\text { Chem } / 180 / 30\end{array}$ & $\begin{array}{c}\mathrm{HCl}+\text { water } \\
\mathrm{HCl}+\text { water } \\
\text { Water } \\
\mathrm{HNO} 3+\text { water } \\
\mathrm{HCl}+\text { water } \\
\mathrm{HNO} 3+\text { water } \\
\mathrm{HCl} \\
\mathrm{HCl}+\text { water }\end{array}$ \\
\hline \multicolumn{3}{|c|}{ Nanotube structure: Anatase $\mathrm{TiO}_{2} / \mathrm{H}_{2} \mathrm{Ti}_{3} \mathrm{O}_{7} \cdot 0.5 \mathrm{H} 2 \mathrm{O}$} \\
\hline Rutile & Chemi $/ 110 / 4^{b}$ & HNO3 + water \\
\hline \multicolumn{3}{|c|}{ Nanotube structure: $\mathrm{A}_{2} \mathrm{Ti}_{2} \mathrm{O}_{5} \cdot \mathrm{H} 2 \mathrm{O}$} \\
\hline $\begin{array}{c}\mathrm{TiO}_{2} \text { powder } \\
\text { Anatase }\end{array}$ & $\begin{array}{l}\text { Chem/110/20 } \\
\text { Chem/110/20 }\end{array}$ & $\begin{array}{l}\mathrm{HCl}+\text { water } \\
\mathrm{HCl}+\text { water }\end{array}$ \\
\hline \multicolumn{3}{|c|}{ Nanotube structure: A2Ti3O7 } \\
\hline $\begin{array}{c}\text { Anatase } \\
\text { Anatase } \\
\text { Anatase } \\
\text { Anatase/rutile } \\
\text { Any crystals } \\
\text { Anatase } \\
\text { Anatase } \\
\text { Rutile } \\
\text { Anatase/rutile }\end{array}$ & $\begin{array}{l}\text { Hydro/130/72 } \\
\text { Hydro/130/72 } \\
\text { Hydro/130/72 } \\
\text { Hydro/150/20 } \\
\text { Hydro/130/72 } \\
\text { Hydro/180/48 } \\
\text { Hydro/180/24 } \\
\text { Hydro/150/72 } \\
\text { Hydro/130/72 }\end{array}$ & $\begin{array}{c}\mathrm{HCl}+\text { water } \\
\mathrm{HCl}+\text { water } \\
\text { Water } \\
\text { Water } \\
\text { Water } \\
\text { Water } \\
\mathrm{HCl}+\text { water } \\
\mathrm{HCL}+\text { water } \\
\text { Water }\end{array}$ \\
\hline \multicolumn{3}{|c|}{ Nanotube structure: $\mathrm{H}_{2} \mathrm{Ti}_{4} \mathrm{O}_{9} \cdot \mathrm{H}_{2} \mathrm{O}$} \\
\hline Anatase/rutile & Hydro/110/96 & $\mathrm{HCl}+$ water \\
\hline \multicolumn{3}{|c|}{ Nanotube structure: Lepidocrocite Titanates } \\
\hline $\begin{array}{l}\text { Anatase } \\
\text { Anatase }\end{array}$ & $\begin{array}{l}\text { Hydro/150/48 } \\
\text { Hydro/130/24 }\end{array}$ & $\begin{array}{l}\text { Water }+\mathrm{HCl} \\
\text { Water }+\mathrm{HCl}\end{array}$ \\
\hline
\end{tabular}

${ }^{a}$ Treatment conditions refer to chemical or hydrothermal processes, temperature $\left({ }^{\circ} \mathrm{C}\right)$, and duration (h), respectively. ${ }^{\mathrm{b}}$ Sonication at $280 \mathrm{~W}$ before chemical treatment.

The $\mathrm{TiO}_{2}$ nanoparticle used in DSSCs are usually as a random network of crystallographically misaligned crystallites, and lattice mismatches at the grain boundaries could influence electron scattering and act as electron trap has been found to limit the electron transport and reduce the electron lifetime [43, 44] as shown in Fig. 8, even though the small size of $\mathrm{TiO}_{2}$ nanoparticle can provide a large surface area and capability to adsorb enough dye for efficient light harvesting and a relative high conversion efficiency [43]. If decrease the $\mathrm{TiO}_{2}$ nanoparticle film thickness will be influence decreasing of the resistance to electron transport and decrease the surface area of $\mathrm{TiO}_{2}$ nanoparticle [45]. Replacing the $\mathrm{TiO}_{2}$ nanoparticles with a dense network of wide-band-gap semiconductor nanowires may be advantageous because of low cost, high efficiency, simple in preparation and the nanowire morphology provides direct conduction paths for the 


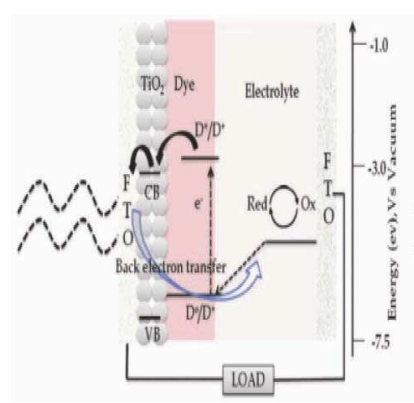

(a)

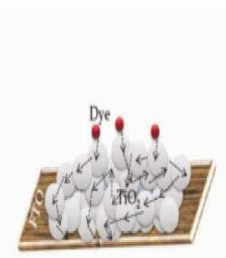

(c)

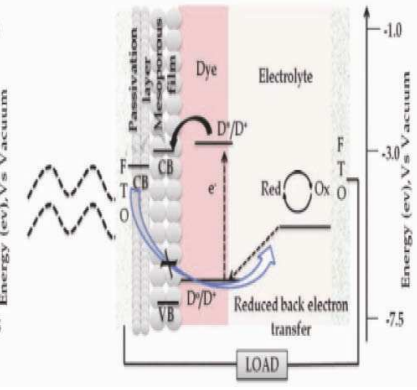

(b)

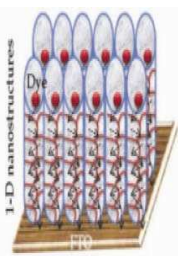

(d)
Fig. 8. Schematic representation of spherical anatase $\mathrm{TiO} 2$ nanoparticles based DSSCs, where back electron transfer/recombination is the major role for loss of conversion efficiency (a), photoelectrode with lower passivation layer and upper anatase mesoporous $\mathrm{TiO} 2$ to minimize the back electron transfer (b), random electron diffusion through spherical $\mathrm{TiO} 2$ nanoparticles (c), and 1-D nanostructures of $\mathrm{TiO} 2$ with directional electron diffusion (d) [46].

electrons from the point of injection to the collection electrode while maintaining high surface area for dye adsorption [45].

One-dimensional nanostructures is a way to improve the diffusion mechanism, and therefore, transport properties is to grow the electrode materials such as nanotubes, and nanorods, nanowires, and nanofibers [8, 45, 47]. Fig. 9 describes differentiate the schematic of electron diffusion between nanoparticle and onedimensional while in Fig. 10 explains the concept of channeled electron transport through one-dimensional nanostructures. Meanwhile, Fig. 11 show the comparison of J-V characteristics between nanoparticle and nanorods. Based on the J-V characteristics, one dimensional nanostructures show better performance than nanoparticle. In nanowires, electron transport performance is faster than percolation through a nanoparticles network because of a large surface area for dye adsorption [47]. Beside, nanorods or nanotubes also known as nanowires have been considered as alternatives to nanoparticles [48].

Oriented one-dimensional nanostructures such nanowires arrays, incorporating DSSSC have large

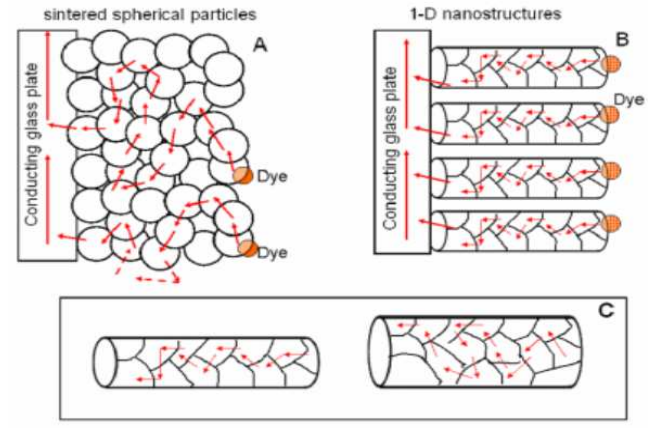

Fig. 9. Schematic of electron diffusion between (A) sintered spherical nanoparticles and (B) one-dimensional (1-D) nanostructures. Electron diffusion through spherical nanoparticles is according to random walk model. Though diffusion is in accordance with the random walk in 1-D structures also, the electrons are constrained to move directionally. The panel " $C$ "' shown in the box explains how reduction of diameter of the 1-D structure make the electron flow more channeled [8].

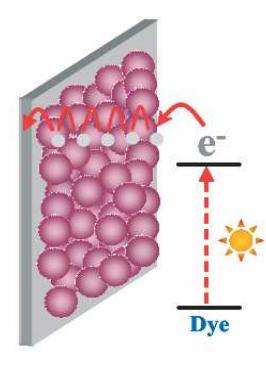

nanoparticle

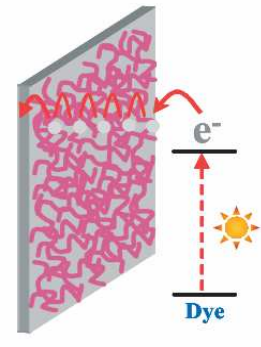

$\sim N$ nanorod
Fig. 10. Simple representation of $\mathrm{TiO}_{2} \mathrm{NP}$ and NR based photoanodes on the FTO coating glass substrate [48].

potentially to improve the charge-collection efficiency by promoting faster transport and slower recombination [49, 50]. There are several methods allow growth of nanowires nearly vertically from the substrate [45] such synthesis $\mathrm{TiO}_{2}$ nanowire films arrays can be achieved via a hydrothermal process [51]. According to [51], the synthesis process for the fabrication of highly aligned, vertically oriented, densely packed, and highly crystalline nanowire arrays on FTO-coated glass was performed by treating the FTO glass with $0.2 \mathrm{M} \mathrm{TiCl}{ }_{4}$ aqueous solution for $12 \mathrm{~h}$ and subsequently heating in air at $500^{\circ} \mathrm{C}$ for $30 \mathrm{~min}$ placed within a sealed Teflon reactor containing $10 \mathrm{~mL}$ of toluene, $1 \mathrm{~mL}$ of tetrabutyl titanate, $1 \mathrm{~mL}$ of $1.0 \mathrm{M}$ titanium tetrachloride (in toluene), and $1 \mathrm{mLof}$ hydrochloric acid (37wt \%). With an increase in temperature, Ti4+ precursors hydrolyze with water at the water $/ \mathrm{TiO}_{2}$ or FTO interface, resulting in the formation of a crystal nucleus on the substrate. After formation of 


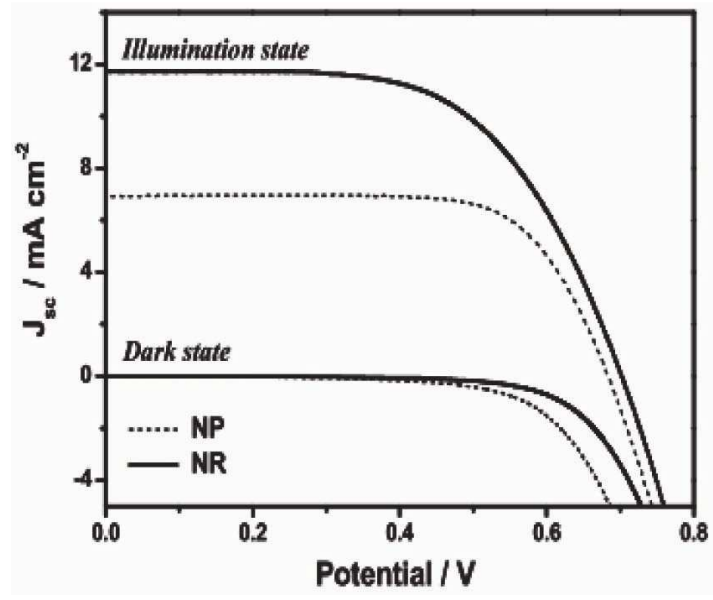

(a)

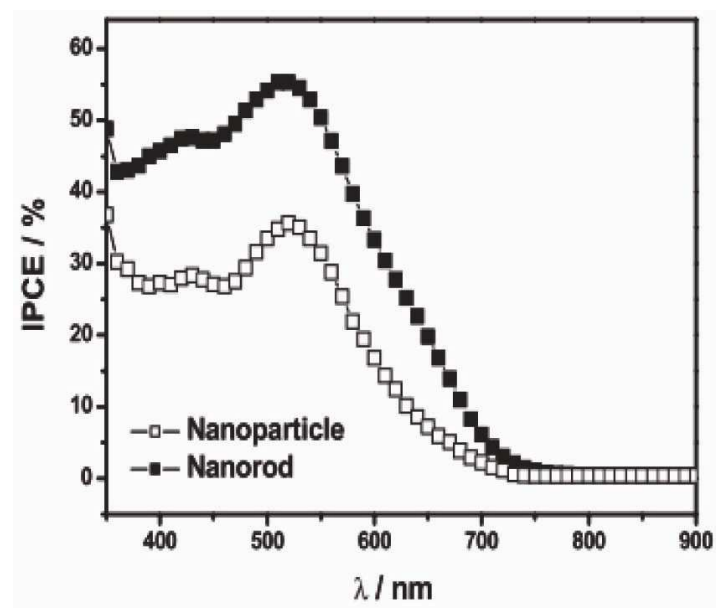

(b)

Fig. 11. J-V characteristics of NP- and NR-based dyesensitized solar cells. The illumination intensity of $100 \mathrm{mWcm}-$ 2 with AM 1.5 and active area of $0.25 \mathrm{~cm}^{2}$ were applied [48].

the first nanocrystalline layer, a new interface forms between hydrophilic $\mathrm{TiO}_{2}$ and toluene with continuous hydrolysis and subsequent growth-crystallization. A reaction temperature of $180^{\circ} \mathrm{C}$ was used with reaction times lasting from $30 \mathrm{~min}$ to $48 \mathrm{~h}$. Nanowire growth was found to slow with time; for example, a $2 \mathrm{~h}$ reaction resulted in $2.1 \mu \mathrm{m}$ long nanowires, a $4 \mathrm{~h}$ reaction leads to $3.2 \mu \mathrm{m}$-long nanowires, $8 \mathrm{~h}$ to $3.8 \mu \mathrm{m}$, and $22 \mathrm{~h}$ to $4 \mu \mathrm{m}$; no increase in nanowire length was achieved for reaction times beyond $22 \mathrm{~h}$. After the reaction period, the nanowire samples were removed, washed with ethanol, and then dried in air. However, randomly oriented is disordered and random. It has not realized the direct electron transport. While for vertically oriented, the small surface area made the photoelectrochemistry properties

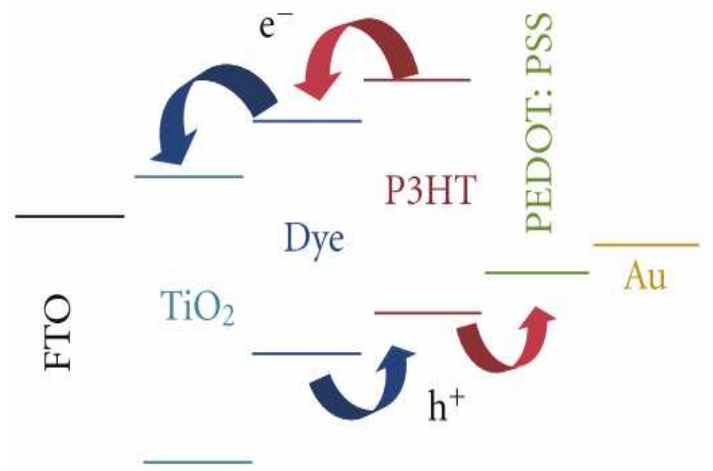

Fig. 12. Depiction of energy level positions and charge transfer processes of the constituent layers of the described hybrid solar cell [51].

worse than the randomly oriented $1 \mathrm{D} \mathrm{TiO}_{2}$ nanomaterial [43].

The ability to improve charge transport using high aspect ratio nanostructures has been observed in nanowires-polymer blend solar cells, where external quantum efficiency increases from $20 \%$ to almost $60 \%$ as the length of the nanorods are increased from 7 to $60 \mathrm{~nm}$ [45]. A new configuration is $\mathrm{FTO} / \mathrm{TiO}_{2} \mathrm{NWs} / \mathrm{P} 3 \mathrm{HT}$ PCBM/PEDOT:PSS/gold, with illumination through the FTO-glass substrate. The conduction band position of $\mathrm{TiO} 2$ is just below the LUMO energy level of PCBM, resulting in efficient extraction of electrons from the PCBM. The nanowires architecture enhances the interfacial contact area between $\mathrm{TiO}_{2}$ and $\mathrm{P} 3 \mathrm{HT}$ and/or PCBM of the active blend layer, which implies a higher electron collecting surface area [51].

\section{CONCLUSIONS}

In overall, dye-sensitized solar cell is a third generation of solar cell, which is promising a low cost photovoltaic device. In order to solve the trapping/detrapping events during electron transport, nanowires are applied to enhance the electron transport. Nanowires act as new medium for to improve electron transport as well as to solve the trapping/detrapping events. Combination technique and application of DSSC and nanowires in solar cloth, which is as new photovoltaic device, will increase the performance and efficiency. As the nanonets would have superior percolation behavior compared to the nanoparticle analogues, the nanonets would be considered for 
developing solar cloths as a medium for electron and hole-conductor transport. This review has hopefully given the reader some insights into the parameters determining the efficiencies of electron injection and dye regeneration in dye sensitized photo electrochemical solar cells [2].

\section{ACKNOWLEDGMENTS}

First and foremost, the author would like to thanks Universiti Teknikal Malaysia Melaka, Malaysia (UTeM) for their equipment, financial and assistance support. This project was supported by Malaysian Technical University Network Grant; MTUN/2012/UMPFKEKK/2-M00006. Last but not list, the author would like to thanks those involved direct and indirect in completing this project success fully.

\section{REFERENCES}

[1] A. Jena, S. P. Mohanty, P. Kumar, J. Naduvath, P. Lekha, J. Das, H. K. Narula, S. Mallick, P. Bhargava, and V. Gondane, "Dye Sensitized Solar Cells $\square$ : A Review," no. January 2013, pp. 37-41.

[2] M. M. Byranvand, A. N. Kharat, and A. R. Badiei, "Electron Transfer in Dye-Sensitized Nanocrystalline TiO 2 Solar Cell," vol. 2, pp. 1926, 2012.

[3] Y. Jiao, F. Zhang, and S. Meng, "Fabricated Dye Sensitized Solar Cells ( DSSCs ),” pp. 5-37, 1991.

[4] A. S. Karmakar and J. P. Ruparelia, "A Critical Review on Dye Sensitized Solar Cells," pp. 8-10, 2011.

[5] N.-G. Park, "Dye-Sensitized Metal Oxide Nanostructures and Their Photoelectrochemical Properties," Journal of the Korean Electrochemical Society, vol. 13, no. 1, pp. 10-18, Feb. 2010.

[6] Q. Zhang and G. Cao, "Nanostructured photoelectrodes for dye-sensitized solar cells," 2011.

[7] Y. Chergui, N. Nehaoua, and D. E. Mekki, "Comparative Study of Dye-Sensitized Solar Cell Based on $\mathrm{ZnO}$ and TiO 2 Nanostructures," 2010.

[8] R. Jose, V. Thavasi, and S. Ramakrishna, "Metal Oxides for Dye-Sensitized Solar Cells," Journal of the American Ceramic Society, vol. 92, no. 2, pp.
289-301, Feb. 2009.

[9] M. Grätzel and J. R. Durrant, "DYE-SENSITISED MESOSCOPIC SOLAR CELLS,” 1912.

[10] J.-J. Wu, G.-R. Chen, C.-C. Lu, W.-T. Wu, and J.-S, Chen, "Performance and electron transport properties of $\mathrm{TiO}(2)$ nanocomposite dye-sensitized solar cells.," Nanotechnology, vol. 19, no. 10, p. 105702, Mar. 2008.

[11] K. E. Jasim, "Dye Sensitized Solar Cells - Working Principles, Challenges and Opportunities," 2007.

[12] N.-G. Park, "Methods to Improve Light Harvesting Efficiency in Dye-Sensitized Solar Cells," Journal of Electrochemical Science and Technology, vol. 1, no. 2, pp. 69-74, Dec. 2010.

[13] K. Hara, H. Arakawa, and C. Dssc, Dye-sensitized Solar Cells. 2003.

[14] P. Tiwana, P. Docampo, M. B. Johnston, H. J. Snaith, and L. M. Herz, "Electron Mobility and Injection $\mathrm{SnO} 2$, and $\mathrm{TiO} 2$ Films Used in DyeSensitized Solar Cells," no. 6, pp. 5158-5166, 2011.

[15] K. Nazeeruddin, E. Baranoff, and M. Gra, "Dyesensitized solar cells $\square$ : A brief overview," vol. 85, pp. 1172-1178, 2011.

[16] A. Bally, "ELECTRONIC PROPERTIES OF NANO-CRYSTALLINE TITANIUM DIOXIDE THIN FILMS," vol. 2094, 1999.

[17] J. Halme, "Dye-sensitized nanostructured and organic photovoltaic cells $\square$ : technical review and preliminary tests," 2002.

[18] M. M. Cogliati and M. Porro, "Third Generation Solar Cells $\square$ : Modeling and Simulation," 2010.

[19] W. A. V. L, C. A. Q. S, and J. A. H. S, "The Chemistry and Physics of Dye-Sensitized Solar Cells," 1991.

[20] I. Chung, B. Lee, J. He, R. P. H. Chang, and M. G. Kanatzidis, "All-solid-state dye-sensitized solar cells with high efficiency.," Nature, vol. 485, no. 7399, pp. 486-9, May 2012.

[21] L. Deng, "DYE-SENSITIZED SOLAR CELLS WITH A SOLID HOLE CONDUCTOR," 2012.

[22] M. P. F. Graça, C. C. Silva, L. C. Costa, and M. A. Valente, "Study of the structural, morphological and electric characteristics of $\mathrm{TiO} 2$ nanopowders .," vol. 3, pp. 99-111, 2010.

[23] B. E. Hardin, H. J. Snaith, and M. D. McGehee, "The renaissance of dye-sensitized solar cells," Nature Photonics, vol. 6, no. 3, pp. 162-169, Feb. 
2012.

[24] M. Kim and Y. Kwon, "Semiconductor $\mathrm{CdO}$ as a Blocking Layer Material on DSSC Electrode : Mechanism and Application,” pp. 17176-17182, 2009.

[25] B. Tian, T. J. Kempa, and C. M. Lieber, "Single nanowire photovoltaics.," Chemical Society Reviews, vol. 38, no. 1, pp. 16-24, 2009.

[26] M. S. Dresselhaus, Y. M. Lin, O. Rabin, M. R. Black, and G. Dresselhaus, "Nanowires," 2003.

[27] A. I. Hochbaum and P. Yang, "Semiconductor Nanowires for Energy Conversion,” pp. 527-546, 2010.

[28] C. M. Lieber, "Semiconductor nanowires $\square$ : A platform for nanoscience and nanotechnology," vol. 36, no. December, pp. 1052-1064, 2011.

[29] W. Lu and C. M. Lieber, "Semiconductor nanowires," vol. 39, 2006.

[30] B. Tian and C. M. Lieber, "Design, synthesis , and characterization of novel nanowire structures for photovoltaics and intracellular probes *," vol. 83, no. 12, pp. 2153-2169, 2011.

[31] J. Shi and X. Wang, "Functional semiconductor nanowires via vapor deposition," Journal of Vacuum Science \& Technology B: Microelectronics and Nanometer Structures, vol. 29, no. 6, p. 060801, 2011.

[32] G. M. Bakhshkandi Roya, "Growth of $\mathrm{TiO} 2$ Nanorods by HFCVD," Life Science Journal, vol. 10, no. 1, pp. 424-430, 2013.

[33] S. K. Pradhan, P. J. Reucroft, F. Yang, and A. Dozier, "Growth of $\mathrm{TiO} 2$ nanorods by metalorganic chemical vapor deposition," Journal of Crystal Growth, vol. 256, no. 1-2, pp. 83-88, Aug. 2003.

[34] C. Tsai and H. Teng, "Structural Features of Nanotubes Synthesized from $\mathrm{NaOH}$ Treatment on TiO 2 with Different Post-Treatments," no. 4, pp. 367-373, 2006.

[35] M. Rodríguez-Reyes and H. J. Dorantes-Rosales, "A simple route to obtain $\mathrm{TiO} 2$ nanowires by the sol-gel method," Journal of Sol-Gel Science and Technology, vol. 59, no. 3, pp. 658-661, Jul. 2011.

[36] L. Miao, S. Tanemura, S. Toh, and K. Kakeko, "Preparation of TiO 2 Nanorods by Heating Sol Gel Template Method."

[37] G. She, L. Mu, and W. Shi, "Electrodeposition of one-dimensional nanostructures.," Recent patents on nanotechnology, vol. 3, no. 3, pp. 182-91, Jan. 2009.

[38] Z. G. Shang, Z. Q. Liu, P. J. Shang, and J. K. Shang, "Synthesis of Single-Crystal TiO 2 Nanowire Using Titanium Monoxide Powder by Thermal Evaporation," vol. 28, no. 5, pp. 385-390, 2012.

[39] W. Lu, P. Xie, and C. M. Lieber, "Nanowire Transistor Performance Limits and Applications," vol. 55, no. 11, pp. 2859-2876, 2008.

[40] Y. V Kolen'ko, K. a Kovnir, A. I. Gavrilov, A. V Garshev, J. Frantti, O. I. Lebedev, B. R. Churagulov, G. Van Tendeloo, and M. Yoshimura, "Hydrothermal synthesis and characterization of nanorods of various titanates and titanium dioxide.," The journal of physical chemistry. $B$, vol. 110, no. 9, pp. 4030-8, Mar. 2006.

[41] Z.-Y. Yuan and B.-L. Su, "Titanium oxide nanotubes, nanofibers and nanowires," Colloids and Surfaces A: Physicochemical and Engineering Aspects, vol. 241, no. 1-3, pp. 173-183, Jul. 2004.

[42] M. T. Borgstr, J. Wallentin, M. Heurlin, F. Stefan, P. Wickert, J. Leene, M. H. Magnusson, K. Deppert, and L. Samuelson, "Nanowires With Promise for Photovoltaics," vol. 17, no. 4, pp. 1050-1061, 2011.

[43] J. Qu and C. Lai, "One-Dimensional TiO 2 Nanostructures as Photoanodes for Dye-Sensitized Solar Cells," vol. 2013, 2013.

[44] S. Cells, "Hierarchical Oriented Anatase TiO 2 Nanostructure arrays on Flexible Substrate for Efficient Dye-sensitized," pp. 1-7, 2013.

[45] J. B. Baxter and E. S. Aydil, "Nanowire-based dyesensitized solar cells," pp. 1-3, 2005.

[46] J. Lee, M. Rahman, S. Sarker, N. C. D. Nath, A. J. S. Ahammad, and J. K. Lee, "Metal Oxides and Their Composites for the Photoelectrode of Dye Sensitized Solar Cells, 2010.

[47] M. Law, L. E. Greene, J. C. Johnson, R. Saykally, and P. Yang, "Nanowire dye-sensitized solar cells.," Nature materials, vol. 4, no. 6, pp. 455-9, Jun. 2005.

[48] B. Soon, H. Kang, S. Choi, M. Kang, J. Kim, and H. Kim, "Nanorod-Based Dye-Sensitized Solar Cells with Improved Charge Collection Efficiency **," pp. 54-58, 2008.

[49] K. Zhu, N. R. Neale, A. Miedaner, and A. J. Frank, 
"Enhanced charge-collection efficiencies and light scattering in dye-sensitized solar cells using oriented TiO2 nanotubes arrays.," Nano letters, vol. 7, no. 1, pp. 69-74, Jan. 2007.

[50] J. R. Jennings, A. Ghicov, L. M. Peter, P. Schmuki, and A. B. Walker, "Dye-sensitized solar cells based on oriented $\mathrm{TiO} 2$ nanotube arrays: transport, trapping, and transfer of electrons.," Journal of the American Chemical Society, vol. 130, no. 40, pp. 13364-72, Oct. 2008.

[51] N. Bao, X. Feng, and C. a. Grimes, "SelfOrganized One-Dimensional TiO2 Nanotube/ Nanowire Array Films for Use in Excitonic Solar Cells: A Review," Journal of Nanotechnology, vol. 2012, pp. 1-27, 2012.

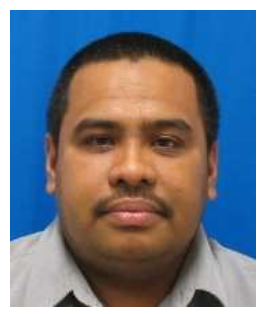

Mohd Azlishah Othman was graduated with Degree Bachelor of Engineering in Electrical Engineering (Telecommunication) from Universiti Teknologi Malaysia (UTM) on 2003. In September 2005 he joined Universiti Teknikal Malaysia Melaka (UTeM) as a Lecturer at Fakulti Kej. Elektronik dan Kej. Komputer (FKEKK). He received his Master's Degree in Computer and Communication Engineering from University of Nottingham, UK on 2005 and graduated received his $\mathrm{PhD}$ in Electrical and Electronic Engineering in University of Nottingham, UK on 2013. His research interest is in the field of Terahertz circuits and devices. He is also an active researcher with a good track record with a number of research projects in RF and Microwave Engineering.

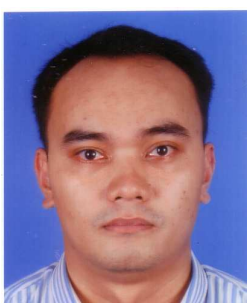

Badrul Hisham Ahmad graduated with honours degree in Electronic and Communication Engineering from the University of Leeds, UK in 1998. He received the M.Sc. degree from University Kebangsaan Malaysia in 2003 and Ph.D. degree from Leeds University, United Kingdom for a thesis on the design and development of SIW filters in 2008. He is a lecturer in Universiti Teknikal Malaysia Melaka since 2003. He is also an active researcher with a good track record with a number of research projects in RF and Microwave Engineering.

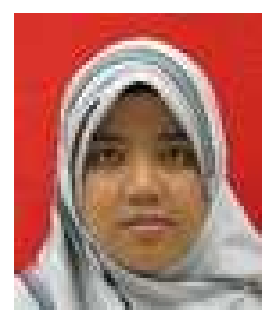

Noor Faridah Amat graduated with honours degree in Electronic Engineering (Industrial Electronic) from the Universiti Teknikal Malaysia Melaka in 2012. She continues study in M.Sc. by research in Universiti Teknikal Malaysia Melaka. The field of research is about dye sensitized solar cells. 